\title{
Weight change in patients with differentiated thyroid carcinoma after total thyroidectomy versus lobectomy
}

\author{
Hae-Ryong Cho, Ra-Yeong Song, Kyung Ho Kang \\ Department of Surgery, Chung-Ang University Hospital, Chung-Ang University College of Medicine, Seoul, Korea
}

Purpose: Thyroid hormone is an important hormone in maintaining metabolism and homeostasis in the body. There exists a common perception among patients that thyroid surgery will cause weight gain. Prevention of any undesired weight gain could be important for the maintenance of well-being in most patients. Our study compares changes in body mass index (BMI) and weight after total thyroidectomy or lobectomy in thyroid cancer patients.

Methods: A total of 967 patients with differentiated thyroid carcinoma were enrolled in the study, from March 2011 to July 2016 at ChungAng University Hospital. Exclusion criteria were less than lobectomy, modified radical neck dissection, recurred operation, and combined operation for other causes. Primary endpoints were change in body weight and BMl at 2 years after surgery. A subgroup analysis was performed for patients with significant weight change.

Results: There were no differences between both groups in BMI after 2 years of thyroid operation. Thyroid stimulating hormone (TSH) levels were not significantly different. Fifteen percent of patients showed significant change in body weight after 2 years of operation. The subgroup analysis of these patients showed no significant differences in gender, age, or extent of operation between those who had gained weight compared to those who had lost weight. There were also no differences in postoperative TSH levels, levothyroxine supplementation, or radioactive iodine treatment.

Conclusion: There was a minimal postoperative increase in mean BMI over the years in patients undergoing thyroidectomy for differentiated thyroid cancer. However, weight change did not differ in those undergoing thyroid lobectomy or total thyroidectomy.

Keywords: Thyroidectomy, Thyroid neoplasms, Weight, Body mass index

\section{INTRODUCTION}

The role of thyroid hormones in diverse processes related to metabolism, growth, and development is well known [1]. The effects

\footnotetext{
Received: Oct 19, 2020 Revised: Oct 30, 2020 Accepted: Nov 2, 2020 Correspondence to: Ra-Yeong Song Department of Surgery, Chung-Ang University Hospital, Chung-Ang University College of Medicine, 102 Heukseok-ro, Dongjak-gu, Seoul 06973, Korea

Tel: +82-2-6299-3187, Fax: +82-2-824-7869

E-mail: rayeong_s@hotmail.com
}

ORCID: Hae-Ryong Cho (https://orcid.org/0000-0001-8256-1204), Ra-Yeong Song (https://orcid.org/0000-0001-8994-6131), Kyung Ho Kang (https://orcid.org/00000002-9778-1725)

Copyright (C) 2020 Korean Society of Surgical Oncology

This is an Open Access article distributed under the terms of the Creative Commons Attribution Non-Commercial License (http://creativecommons.org/licenses/by-nc/4.0) which permits unrestricted non-commercial use, distribution, and reproduction in any medium, provided the original work is properly cited. of excess or deficiency of thyroid hormones can be well seen in patients with hyperthyroidism or hypothyroidism. Hyperthyroid patients commonly show symptoms such as muscle weakness, tachycardia, heat intolerance and weight loss [2]. Patients with hypothyroidism usually complain of fatigue, and weight gain [3].

Thyroidectomy is a common procedure indicated primarily for thyroid cancer as well as benign multinodular goiter. There exists a common perception among patients that thyroid surgery will cause weight gain. Even though weight gain with increasing age is well known, prevention of any undesired weight gain could be important for the maintenance of well-being in most patients. Several studies have addressed this issue with a focus on outcomes of thyroidectomy in patients with hyperthyroidism $[2,4,5]$. Other studies compared outcomes of thyroidectomy in thyroid cancer patients compared to those with benign nodules [6-8]. Our study compares changes in body mass index (BMI) and weight after total thyroidectomy or lobectomy in thyroid cancer patients. 


\section{METHODS}

The medical records of patients who underwent thyroidectomy for thyroid cancer between March 2011 and July 2016 at ChungAng University Hospital were retrospectively reviewed. The study was approved by the Institutional Review Board of Chung-Ang University Hospital (IRB No. 2011-019-19342) and performed in accordance with the principles of the Declaration of Helsinki. Written informed consent was waived. Inclusion criteria were as follows-patients above 18 years of age with primary differentiated thyroid carcinoma (DTC) and preoperatively normal thyroid function. Exclusion criteria were less than lobectomy (e.g., isthmusectomy), modified radical neck dissection, recurred operation, combined operation for other causes, and patients with other malignancies.

We collected demographic data, weight, and BMI of patients before thyroidectomy and at postoperative 1 and 2 years, as well as serum thyroid stimulating hormone (TSH) concentration, operative extent and presence of thyroiditis in pathology report. Preoperative body weight and height were measured at the time of admission for operation. Body weight was measured at each clinic attendance and BMI was calculated as body weight $(\mathrm{kg})$ divided by height $(\mathrm{m})$ squared. Normal range of TSH levels was between 0.55 and $4.78 \mu \mathrm{IU} / \mathrm{mL}$.

Thyroid lobectomy was performed in patients with low risk papillary thyroid cancer and follicular neoplasm. Total thyroidectomy was performed when tumor size was larger than $1 \mathrm{~cm}$, in cases where there were multiple or bilateral tumors, and in patients with metastatic central lymph nodes. The first radioactive iodine (RAI) treatment was performed 3 months after surgery, and the second RAI treatment was done at 6 months after the first RAI treatment. Patients were either withdrawn from levothyroxine (LT4) for 28 days or given recombinant human TSH before each RAI treatment.

A subgroup analysis was performed for patients with significant weight change. We considered a weight change significant when the patient showed consistent weight loss or gain of at least 5\% from preoperative body weight at postoperative 1 year and 2 years follow-up. Patients with weight changes within 5\% (or those who had, for example, gained weight in postoperative year 1 and later lost weight after 2 years) were excluded from this analysis.

For statistical analysis, we used SPSS version 20 (SPSS Inc., Chicago, IL, USA). Categorical variables were expressed as the number and percentage, and compared using the chi-square test. Student $\mathrm{t}$-test was used to assess the relationship between continuous and dichotomous categorical factors. $\mathrm{P}<0.05$ was considered statistically significant.
Table 1. Clinicopathological characteristics

\begin{tabular}{lccr}
\hline Characteristics & $\begin{array}{c}\text { Lobectomy } \\
(\mathrm{n}=148)\end{array}$ & $\begin{array}{c}\text { Total } \\
\text { thyroidectomy } \\
(\mathrm{n}=819)\end{array}$ & P-value \\
\hline Female sex & $119(80.4)$ & $641(78.3)$ & 0.559 \\
Age $(\mathrm{yr})$ & $46.65 \pm 12.70$ & $47.56 \pm 11.65$ & 0.387 \\
Preoperative weight $(\mathrm{kg})$ & $63.40 \pm 13.72$ & $63.12 \pm 11.94$ & 0.795 \\
Preoperative BMI $\left(\mathrm{kg} / \mathrm{m}^{2}\right)$ & $24.31 \pm 4.14$ & $24.19 \pm 3.69$ & 0.707 \\
Preoperative TSH $(\mu \mathrm{IU} / \mathrm{mL})$ & $1.75 \pm 0.92$ & $1.85 \pm 0.93$ & 0.238 \\
CND & $108(73.0)$ & $747(91.2)$ & $<0.001$ \\
Tumor size $(\mathrm{cm})$ & $0.87 \pm 0.83$ & $0.94 \pm 0.76$ & 0.295 \\
T stage & & & $<0.001$ \\
T1a & $96(64.9)$ & $340(41.5)$ & \\
T1b & $24(16.2)$ & $77(9.4)$ & \\
T2 & $5(3.4)$ & $16(2.0)$ & \\
T3 & $23(15.5)$ & $383(46.8)$ & \\
T4a & 0 & $3(0.4)$ & \\
N stage & & & $<0.001$ \\
N0 & $114(76.5)$ & $374(45.7)$ & \\
N1a & $22(15.4)$ & $417(50.9)$ & \\
Nx & $12(8.1)$ & $28(3.4)$ & \\
Thyroiditis & & & \\
Hashimoto's & $26(17.4)$ & $226(27.6)$ & \\
Lymphocytic & $24(16.1)$ & $111(13.6)$ & \\
\hline
\end{tabular}

Values are presented as number (\%) or mean \pm standard deviation. $\mathrm{BMI}$, body mass index; TSH, thyroid stimulating hormone; CND, central neck dissection.

\section{RESULTS}

A total of 967 patients with DTC were enrolled in the study, including 148 who underwent thyroid lobectomy. The mean age of patients was $47.36 \pm 11.73$ years (range, $18-81$ years). The patients of $78.6 \%$ were female. Patient characteristics for each group are shown in Table 1. There were no significant differences in both groups in gender, age, preoperative weight or BMI, and preoperative TSH levels. More patients who underwent total thyroidectomy had undergone central neck dissection (CND; 91.2\% vs. 73.0\%, $\mathrm{P}<0.001)$ and had higher $\mathrm{T}$ stage and $\mathrm{N}$ stage in final pathology $(\mathrm{P}<0.001)$. However, there were no differences in tumor size $(0.94$ $\pm 0.76 \mathrm{~cm}$ vs. $0.87 \pm 0.83 \mathrm{~cm}$ ). Among the 819 patients who underwent total thyroidectomy, 561 patients (68.5\%) received RAI treatment.

Table 2 shows the preoperative and postoperative differences in BMI. There were no differences in BMI after 1 or 2 years of thyroid operation. Postoperative TSH levels at 1 year after operation were higher in the total thyroidectomy group $(11.29 \pm 44.17 \mu \mathrm{IU} / \mathrm{mL}$ vs. $2.62 \pm 20.25 \mu \mathrm{IU} / \mathrm{mL}, \mathrm{P}<0.001$ ). TSH levels at 2 years after operation were not significantly different. Postoperative LT4 supple- 
Table 2. Postoperative changes in lobectomy versus total thyroidectomy patients

\begin{tabular}{lccr}
\hline Variable & $\begin{array}{c}\text { Lobectomy } \\
(\mathrm{n}=148)\end{array}$ & $\begin{array}{c}\text { Total } \\
\text { thyroidectomy } \\
(\mathrm{n}=819)\end{array}$ & P-value \\
\hline Postoperative 1-yr BMI $\left(\mathrm{kg} / \mathrm{m}^{2}\right)$ & $24.36 \pm 3.80$ & $24.20 \pm 3.61$ & 0.609 \\
Postoperative 2-yr BMI $\left(\mathrm{kg} / \mathrm{m}^{2}\right)$ & $24.51 \pm 4.16$ & $24.25 \pm 3.65$ & 0.433 \\
Postoperative 1-yr TSH $(\mu \mathrm{lU} / \mathrm{mL})$ & $2.62 \pm 20.25$ & $11.29 \pm 44.17$ & $<0.001$ \\
Postoperative 2-yr TSH $(\mu \mathrm{lU} / \mathrm{mL})$ & $1.65 \pm 1.15$ & $1.97 \pm 9.55$ & 0.683 \\
Postoperative LT4 supplementation & $107(72.3)$ & $819(100)$ & $<0.001$ \\
RAl treatment & 0 & $561(68.5)$ & $<0.001$ \\
\hline
\end{tabular}

Values are presented as mean \pm standard deviation or number (\%).

BMI, body mass index; TSH, thyroid stimulating hormone; LT4, levothyroxine; $\mathrm{RAl}$, radioactive iodine.

mentation was given in $72.3 \%$ of lobectomy patients. RAI treatment was performed in $68.5 \%$ of total thyroidectomy patients.

One hundred forty-five patients (15.0\%) showed significant change in body weight after 2 years of operation. Sixty-one patients had significant weight loss, while 84 patients had significant weight gain. Clinicopathological features of each group are summarized in Table 3. There were no significant differences in gender, age or extent of operation. The weight loss group had higher preoperative BMI $\left(26.04 \pm 4.08 \mathrm{~kg} / \mathrm{m}^{2}\right.$ vs. $\left.23.00 \pm 3.24 \mathrm{~kg} / \mathrm{m}^{2}\right)$ and mean body weight $(66.72 \pm 11.89 \mathrm{~kg}$ vs. $59.64 \pm 9.29 \mathrm{~kg})$ compared to the weight gain group $(\mathrm{P}<0.001)$. There were no differences in postoperative TSH levels, LT4 supplementation, or RAI treatment.

\section{DISCUSSION}

In this study, we compared changes in body weight and BMI in DTC patients undergoing thyroid lobectomy or total thyroidectomy. Patients did not differ in preoperative anthropometric measurements or preoperative TSH levels. It can be noted that more patients in the total thyroidectomy group underwent CND, and had higher $\mathrm{T}$ stage and $\mathrm{N}$ stage. This is owed to the fact that total thyroidectomy was performed in patients with larger tumor size, and in cases with metastatic central lymph nodes.

Mean BMI gradually increased in postoperative 1 year and 2 years. However, there were no differences in postoperative BMI between lobectomy or total thyroidectomy patients. Differences in postoperative LT4 supplementation were obvious as all total thyroidectomy patients would require hormonal supplementation. Higher TSH levels at postoperative 1 year in the total thyroidectomy group can be attributed to the RAI treatment. Nevertheless, TSH levels at postoperative year 2 were similar between both groups, and weight change did not differ in both groups.

Weight gain after thyroidectomy has been a concern in patients
Table 3. Subgroup analysis of patients with significant weight change

\begin{tabular}{lccr}
\hline Variable & $\begin{array}{c}\text { Weight loss } \\
(\mathrm{n}=61)\end{array}$ & $\begin{array}{c}\text { Weight gain } \\
(\mathrm{n}=84)\end{array}$ & P-value \\
\hline Female sex & $53(56.9)$ & $69(82.1)$ & 0.166 \\
Age $(\mathrm{yr})$ & $48.39 \pm 13.45$ & $44.45 \pm 11.60$ & 0.061 \\
Preoperative weight $(\mathrm{kg})$ & $66.72 \pm 11.89$ & $59.64 \pm 9.29$ & $<0.001$ \\
Preoperative BMI $\left(\mathrm{kg} / \mathrm{m}^{2}\right)$ & $26.04 \pm 4.08$ & $23.00 \pm 3.24$ & $<0.001$ \\
Preoperative TSH $(\mu \mathrm{IU} / \mathrm{mL})$ & $1.97 \pm 1.08$ & $1.71 \pm 0.88$ & 0.109 \\
Operation & & & 0.954 \\
Thyroid lobectomy & $9(14.8)$ & $12(14.3)$ & \\
Total thyroidectomy & $52(85.2)$ & $72(85.7)$ & \\
CND & $52(85.2)$ & $77(91.7)$ & 0.479 \\
Thyroiditis & & & 0.347 \\
$\quad$ Hashimoto's & $23(37.7)$ & $20(23.8)$ & \\
Lymphocytic & $6(9.8)$ & $16(19.0)$ & \\
Postoperative 1-yr BMI $\left(\mathrm{kg} / \mathrm{m}^{2}\right)$ & $23.79 \pm 3.87$ & $25.48 \pm 3.62$ & 0.008 \\
Postoperative 2-yr BMI $\left(\mathrm{kg} / \mathrm{m}^{2}\right)$ & $23.81 \pm 3.66$ & $25.51 \pm 3.62$ & 0.006 \\
Postoperative 1-yr TSH $(\mu \mathrm{IU} / \mathrm{mL})$ & $11.75 \pm 33.76$ & $18.00 \pm 40.79$ & 0.330 \\
Postoperative 2-yr TSH $(\mu \mathrm{IU} / \mathrm{mL})$ & $1.47 \pm 4.53$ & $1.90 \pm 6.50$ & 0.655 \\
Postoperative LT4 supplementation & $55(90.2)$ & $81(96.4)$ & 0.080 \\
\hline RAl treatment & $37(60.7)$ & $57(67.9)$ & 0.391 \\
\hline
\end{tabular}

Values are presented as number (\%) or mean \pm standard deviation.

BMI, body mass index; TSH, thyroid stimulating hormone; CND, central neck dissection; LT4, levothyroxine; RAl, radioactive iodine.

with Graves disease [2,4] and some studies of patients with hypothyroidism have shown weight gain even with normal thyroid function tests [9]. In this study, we excluded cases of abnormal thyroid function before thyroidectomy. Furthermore, patients undergoing thyroidectomy for thyroid cancer usually receive a suppressive dose, or at least a euthyroid dose, of LT4 after surgery. Postoperative normal to low TSH levels could be an explanation to the minimal increase in mean BMI in this study.

Weight gain comes naturally with the increase in age, particularly in the perimenopausal period [10,11]. In a study by Jonklaas and Nsouli-Maktabi [9], change in weight was reviewed in 120 euthyroid patients undergoing thyroidectomy, compared to patients with preexisting Hashimoto's hypothyroidism $(\mathrm{n}=120)$, no thyroid disease $(n=120)$ and, thyroid cancer $(n=120)$. Patients who had undergone thyroidectomy gained more weight than the other groups ( $3.1 \mathrm{~kg}$ vs. 2.2, 1.3, $1.2 \mathrm{~kg}$; $\mathrm{P}<0.05$ ), and the greatest weight gain was in menopausal women ( $4.4 \mathrm{~kg}$ vs. $2.3 \mathrm{~kg}$ in premenopausal women; $\mathrm{P}=0.007$ ). In contrast to this previous report, although statistically insignificant, patients who had gained weight were younger than those who had lost weight, in this study.

Fifteen percent of patients showed significant change in body weight after 2 years of operation. In contrast to the weight loss 
group, those with lower preoperative BMI and mean body weight were subjected to significantly gain weight after thyroidectomy. However, postoperative LT4 supplementation or postoperative TSH levels were similar between both groups. Total thyroidectomy, CND or RAI treatment were not associated with weight gain.

There are some limitations to this study, including its retrospective nature. Moreover, any efforts to lose weight on the part of the patients, as well as eating habits were unaccounted for. Nonetheless, by including only preoperatively euthyroid patients, the possible effects of preoperative thyroid dysfunction on weight gain were controlled. In order to compare the effects of extent of thyroidectomy (lobectomy versus total thyroidectomy), the patients were limited to those with DTC alone. The results from our study may be applicable to patients undergoing thyroidectomy for differentiated thyroid cancer.

In conclusion, there was a minimal postoperative increase in mean BMI over the years in patients undergoing thyroidectomy for differentiated thyroid cancer. However, weight change did not differ in those undergoing thyroid lobectomy or total thyroidectomy.

\section{CONFLICT OF INTEREST}

No potential conflict of interest relevant to this article was reported.

\section{REFERENCES}

1. McAninch EA, Bianco AC. Thyroid hormone signaling in energy homeostasis and energy metabolism. Ann NY Acad Sci 2014; 1311:77-87.

2. Schneider DF, Nookala R, Jaraczewski TJ, Chen H, Solorzano CC, Sippel RS. Thyroidectomy as primary treatment optimizes body mass index in patients with hyperthyroidism. Ann Surg Oncol 2014;21:2303-9.

3. Feller M, Snel M, Moutzouri E, Bauer DC, de Montmollin M, Aujesky D, et al. Association of thyroid hormone therapy with quality of life and thyroid-related symptoms in patients with subclinical hypothyroidism: a systematic review and meta-analysis. JAMA 2018;320:1349-59.

4. Dale J, Daykin J, Holder R, Sheppard MC, Franklyn JA. Weight gain following treatment of hyperthyroidism. Clin Endocrinol (Oxf) 2001;55:233-9.

5. Alonso GT, Rabon S, White PC. Weight gain after treatment of Graves' disease in children. Clin Endocrinol (Oxf) 2018;88:66-70.

6. Singh Ospina N, Castaneda-Guarderas A, Hamidi O, Ponce OJ, Zhen W, Prokop L, et al. Weight changes after thyroid surgery for patients with benign thyroid nodules and thyroid cancer: population-based study and systematic review and meta-analysis. Thyroid 2018;28:639-49.

7. Glick R, Chang P, Michail P, Serpell JW, Grodski S, Lee JC. Body weight change is unpredictable after total thyroidectomy. ANZ J Surg 2018;88:162-6.

8. Sohn SY, Joung JY, Cho YY, Park SM, Jin SM, Chung JH, et al. Weight changes in patients with differentiated thyroid carcinoma during postoperative long-term follow-up under thyroid stimulating hormone suppression. Endocrinol Metab (Seoul) 2015;30:34351.

9. Jonklaas J, Nsouli-Maktabi H. Weight changes in euthyroid patients undergoing thyroidectomy. Thyroid 2011;21:1343-51.

10. Keller C, Larkey L, Distefano JK, Boehm-Smith E, Records K, Robillard A, et al. Perimenopausal obesity. J Womens Health (Larchmt) 2010;19:987-96.

11. Carr MC. The emergence of the metabolic syndrome with menopause. J Clin Endocrinol Metab 2003;88:2404-11. 